\title{
Variations of atmospheric electric field and meteorological pa- rameters in Kamchatka in 1997-2016
}

\author{
Sergey Smirnov ${ }^{1, \star}$ \\ ${ }^{1}$ Institute of Cosmophysical Research and Radio Wave Propagation FEB RAS, Paratunka, Russia
}

\begin{abstract}
Analysis of seasonal and annual variations of aero-electric field at a midlatitudinal observatory Paratunka in Kamchatka was carried out for 1997-2016. Stable seasonal intervals of the highest and the lowest values are observed. Changeability of the annual trend of aero-electric field in the near ground air layer at the observatory located in an active geodynamic region is shown. A large positive trend was changed by a smooth negative one. It is likely to be associated either with radon emanation intensity change in the observatory region or with volcanic activity change in Kamchatka.
\end{abstract}

\section{Introduction}

It is known that meteorological processes and relief have the greatest impact on the dynamic characteristics of atmospheric electricity in the near ground layer. Thus, it was interesting to consider the climate features on Kamchatka peninsular in detail.

"Paratunka" observatory $\left(\varphi=52^{\circ} 58,3^{\prime} N, \lambda=158^{\circ} 14,9^{\prime} E\right)$ is located in the South of Kamchatka peninsular (Fig. 1), to the west from Avacha Bay, in a valley protected by a ridge of small mountains, at the height of $50 \mathrm{~m}$ above the sea level.

\section{Climate and weather in the South of Kamchatka}

The main climate-forming process in the Far East and in Kamchatka is the atmospheric circulation. It contributes the most into the weather state on the whole. Kamchatka location at the eastern edge of Eurasia, for which significant temperature-pressure contrasts, active cyclone activity, reconstruction and change of the general direction of atmospheric circulation meridional components are characteristic, determine the complicated and changeable weather here.

The main climatic centers of atmosphere impact in the northern part of the Pacific Ocean and in Asia are the Aleutian depression and the Siberian maximum in winter, the northern Pacific maximum and the Asian depression in summer, the interaction of which determined the character of the atmospheric circulation in Kamchatka and the seas surrounding it. One of the peculiarities of atmospheric circulation over the South of the peninsular is the active cyclonic activity, especially in autumn-winter period (Fig. 2) [1]. In summer, the cyclonic activity significantly decreases, however, this fall is determined not mainly by the change of cyclone number, but by the decrease of their depth. Recurrence

^Corresponding author: sergey@ikir.ru 


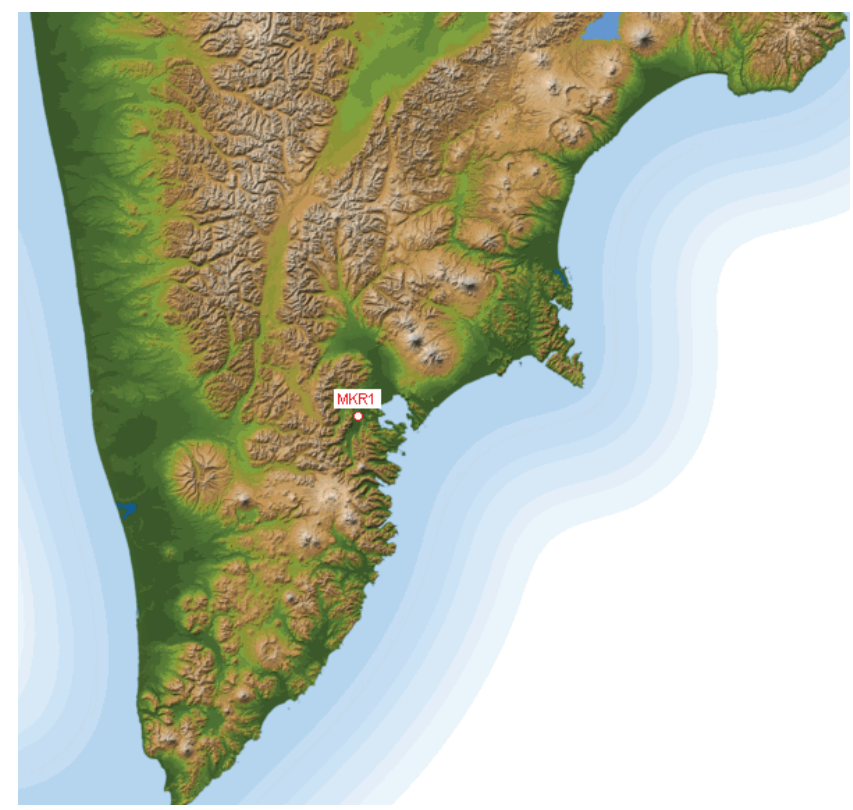

Fig. 1. Location of "Paratunka" observatory on Kamchatka peninsula.

of pressure formations and the circulation character, associated with them, determine the air mass transfer to the south-eastern coast. It is obvious that marine moderate air prevails here within the whole year. The continental moderate air, which is sometimes noted in the north-east of Kamchatka, is just the transformed marine moderate air coming from the Sea of Okhotsk. The Arctic air comes to the region of the observatory in winter from the northern regions of the Bering sea (marine) or from Kolyma regions (continental) significantly transforming on the way.

Fig. 3 illustrates a histogram of atmospheric pressure distribution at the observatory according to a sensor located at the height of 60 meters above the sea level for 2003 and 2004. Stability of readings for May and September indicates that climate changes in a standard way within the summerwinter period. Less predictable are the winter months. The pressure annual variation is completely determined by the circulation processes over the South of Kamchatka and the waters of the Pacific Ocean, the Bering and the Okhotsk seas surrounding the peninsular. Minimum of the average monthly pressure falls on December -January, the period of maximal development of the cyclonic activity in the Aleutian region. This variation refers to the oceanic type, for which small amplitude of annual variation and the maximum within a warm period are typical.

The climatic summer, in contrast to the calendar one, comes when the average day temperature exceeds 10 degrees by centigrade. Stable summer but not necessarily sunny weather in the region of the observatory is observed only in August. Average monthly temperatures for 2003-2009 are shown in Fig. 4, for 2010-2016 in Fig. 5.

Air average annual temperature at the observatory for 2003-2016 is illustrated in Fig. 6. The average over the whole period was $2.7^{\circ} \mathrm{C}$, that corresponds to the value in the paper [1]. It is lower than that in St. Petersburg and in Stockholm located more to the North, at the latitude of more than $60^{\circ}$. 


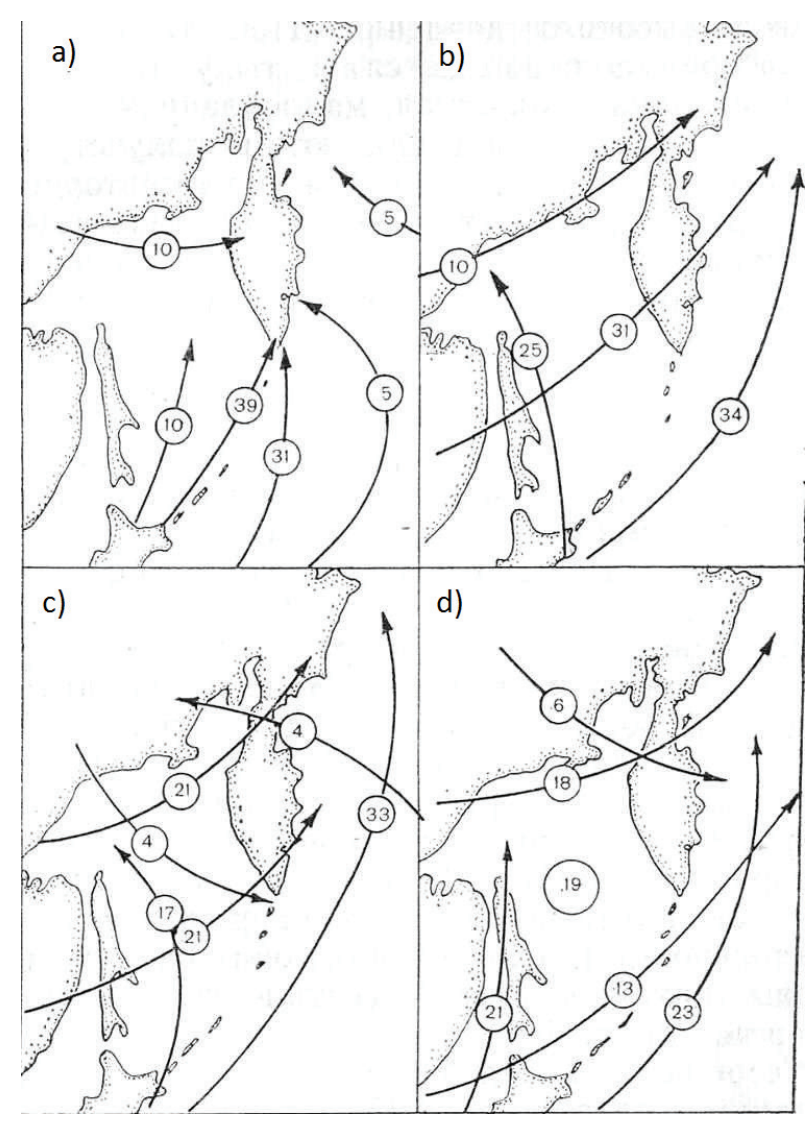

Fig. 2. Typical trajectories of cyclones affecting the weather in the South of Kamchatka and their recurrence [1].

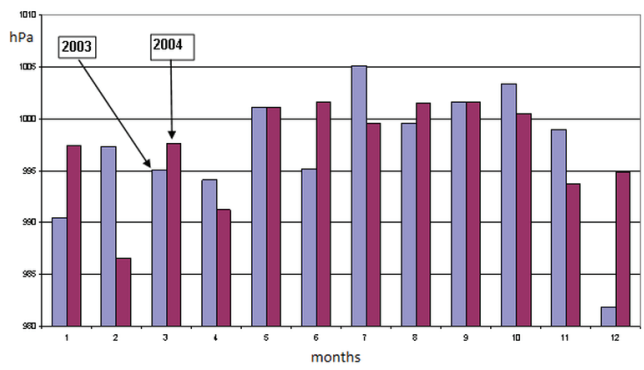

Fig. 3. Histogram of pressure distribution by months for 2003 and 2004.

Wind is horizontal motion of air relatively the earth surface. Wind sensor was mounted on a water tower at the height of 25 meters. Measurements are recorded every 10 minutes. Fig. 7 shows the graphs of wind strength in the region of Paratunka observatory for 2003 and 2004. 


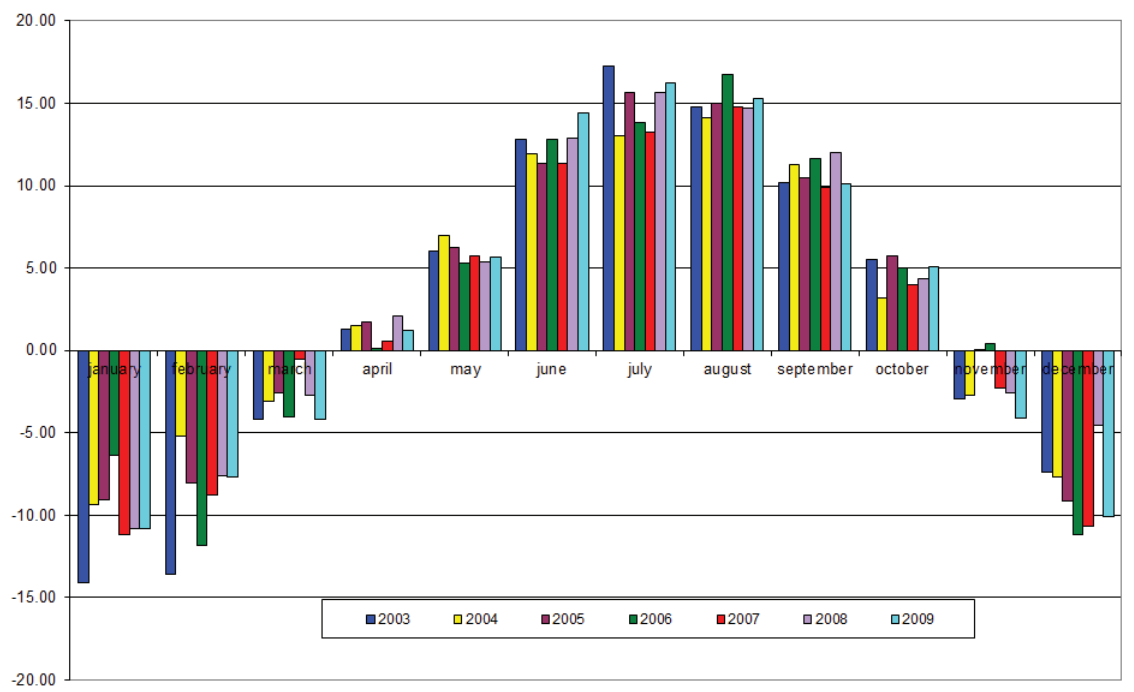

Fig. 4. Annual variation of average monthly temperature for 2003-2009.

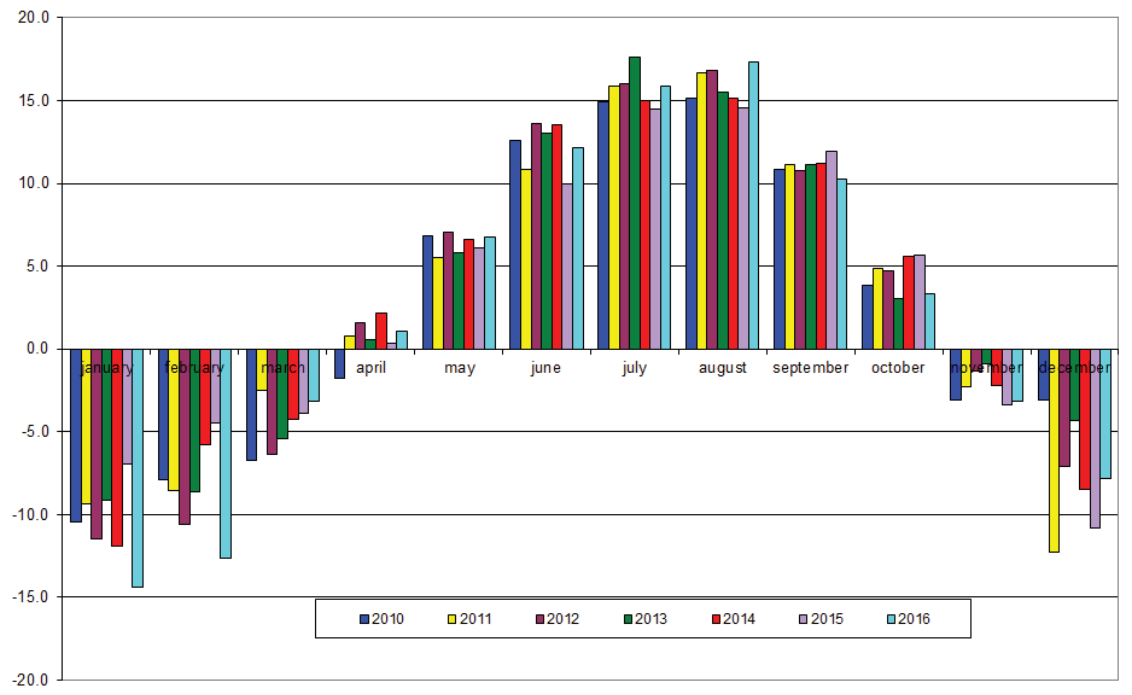

Fig. 5. Annual variation of average monthly temperature for 2010-2016.

Wind is associated with a whole complex of hydro-meteorological characteristics. This relation is clearly seen in the coastal regions. In winter time, fluxes from the sea determine warm weather with precipitation and winds from the mainland (north-western, northern and western in Paratunka) promote dry, cold weather.

Wind regime by the ground surface is formed under the influence of three factors: atmospheric circulation, pressure gradient and the relief. The first two factors are the reason of inter-annual, 


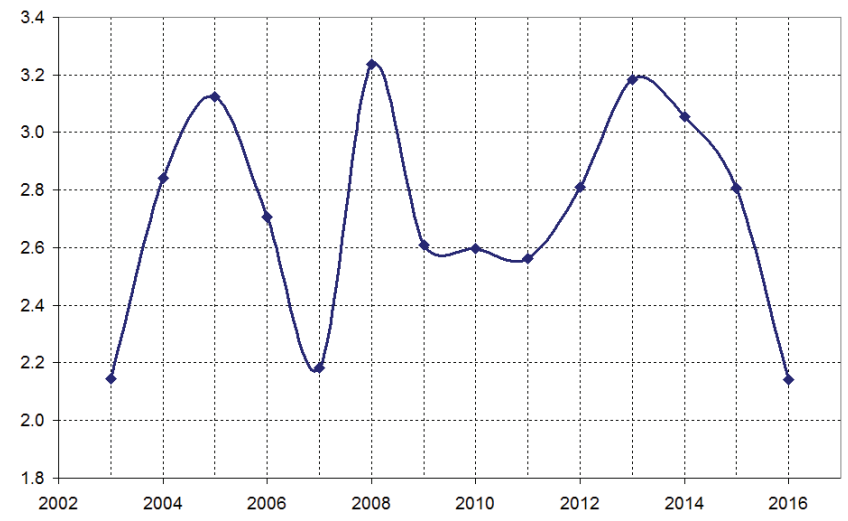

Fig. 6. Average annual temperature for 2003-2016.

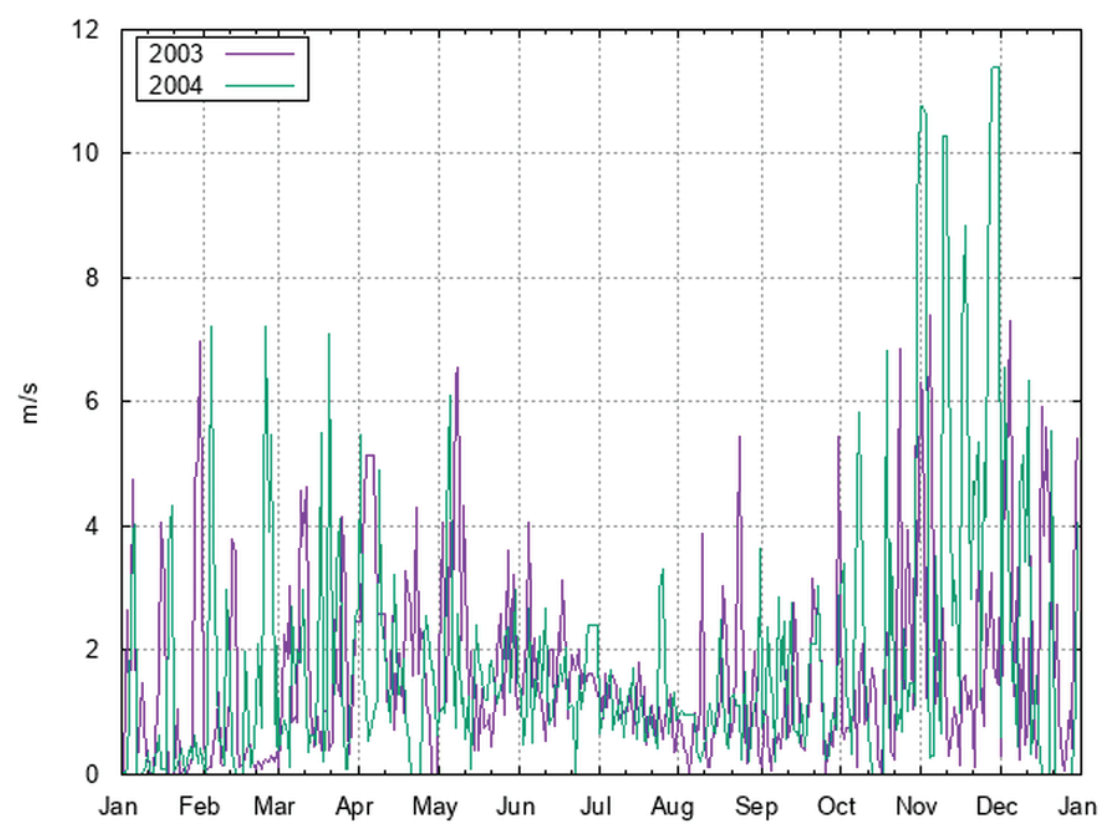

Fig. 7. Wind strength in the region of Paratunka observatory for 2003 and 2004.

seasonal and nonperiodic changes in wind regime. The third one, the relief, manifests itself in the change of wind direction and velocity in the boundary layer, i.e. it introduces some error into the wind regime. Fig. 8 illustrates a wind rose in the region of Paratunka observatory. The highest are the northern and the north-western winds. 


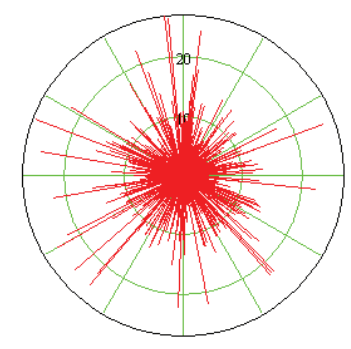

Fig. 8. Wind rose in the region of Paratunka observatory.

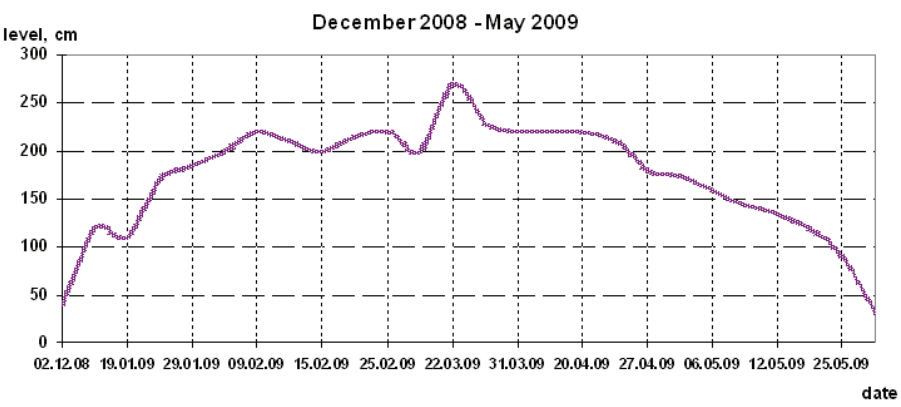

Fig. 9. Snow level in winter 2008-2009.

\section{Precipitation effect on electric field strength}

The strongest meteorological factor affecting the electric field intensity is precipitation. An example of field behavior when precipitation type changed as snow-rain-snow is shown in Fig. 10. The graph of unipolarity (the relation of electrical conductivity caused by positive ions to the electrical conductivity caused by negative ions $K=\lambda_{+} / \lambda_{-}$) during the rain on August 8, 2009 is shown in Fig. The graph of unipolarity during the snowfall on February 26, 2010 is illustrated in Fig. 12. As it is clear from the graphs, these two phenomena are associated with the excess of negative ions (rain) in the first case, and with the excess of positive ions (snow) in the second case. However, there are cases when during strong precipitation they are accompanied by strong sign-variable oscillations. The snow covers the ground in the region of the observatory 7 months a year, from November to the end of May (Fig. 9).

Thunderstorm is an atmospheric phenomenon when multiple electric strokes (lightning) accompanied by thunder occur between separate clouds or between a cloud and the ground. Lightning activity is determined by the processes of atmospheric circulations and mainly by the local physicalgeographical conditions: relief, water proximity. It is characterized by the number of days with lightning and lightning duration.

In the result of insufficient heating, lightning in Kamchatka is quite a rare phenomenon within the warm time of the year. Since 1937 to 1982 (45 years) only 22 lightning strokes were registered. They all, except for two, occurred in summer time. In 1980, there were two lightning strokes and both in winter (in March and in December).

In most cases, summer lightning in the South of Kamchatka occurs during cold front passage at the background of relatively high temperatures. Winter lightning is usually associated with occlusion 


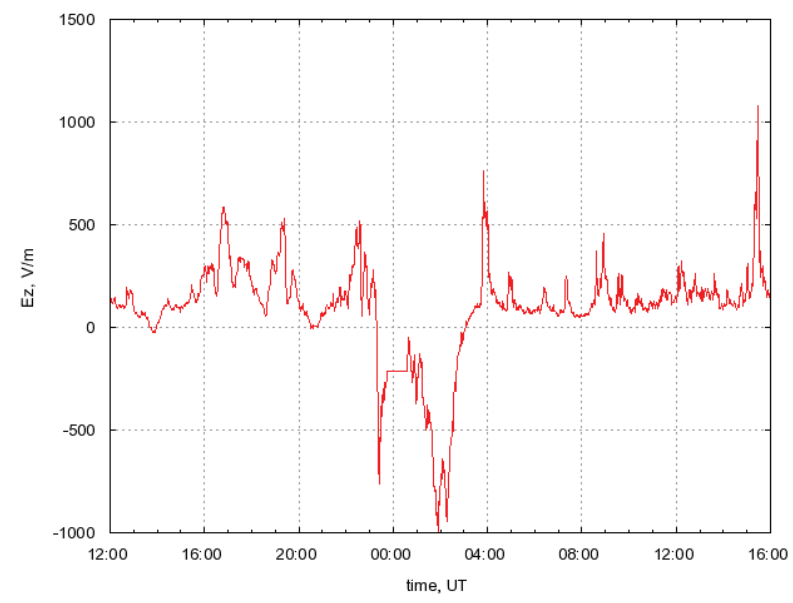

Fig. 10. Electric field behavior in the conditions of precipitation change snow-rain-snow.

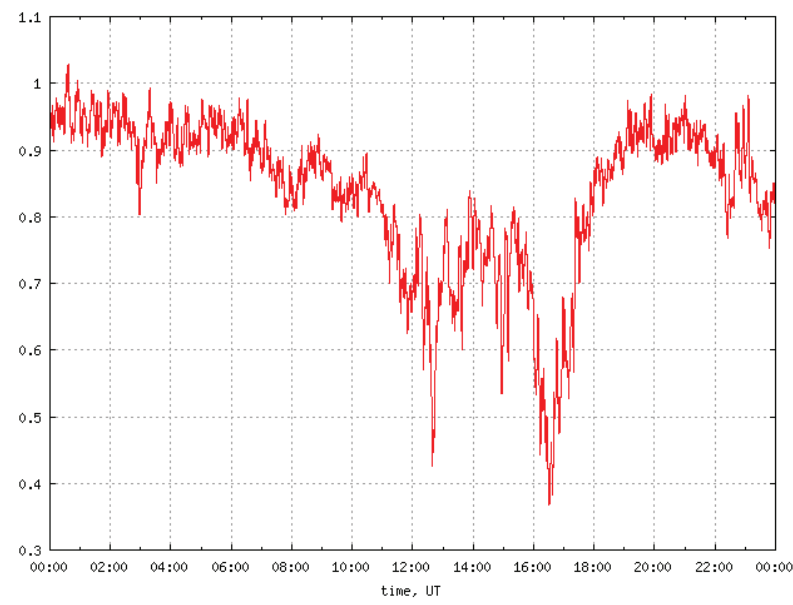

Fig. 11. Graph of unipolarity during the rain on August 8, 2009.

fronts and advection of warm, very humid air mass from the Pacific Ocean. That was just the case, when winter lightning strokes were observed in Petropavlovsk-Kamchatkskiy in March and December 1980 .

Average annual number of days with lightning in Paratunka is less than 0.5, the maximal number is 3 . The average duration of lightning does not exceed 0.5 of an hour per a day with lightning and 0.2 of an hour on the whole for a year. In the annual variation, lightning is the most probable in August (the average number of days with lightning is 0.2 ) and in the diurnal variations, it is from 15 to 18 hours [1].

Hail is a rarer phenomenon than lightning. The average annual number of days with hail is 0.2 , the maximal number is 3. Hail is noted from August to November. By the way, hail was observed 


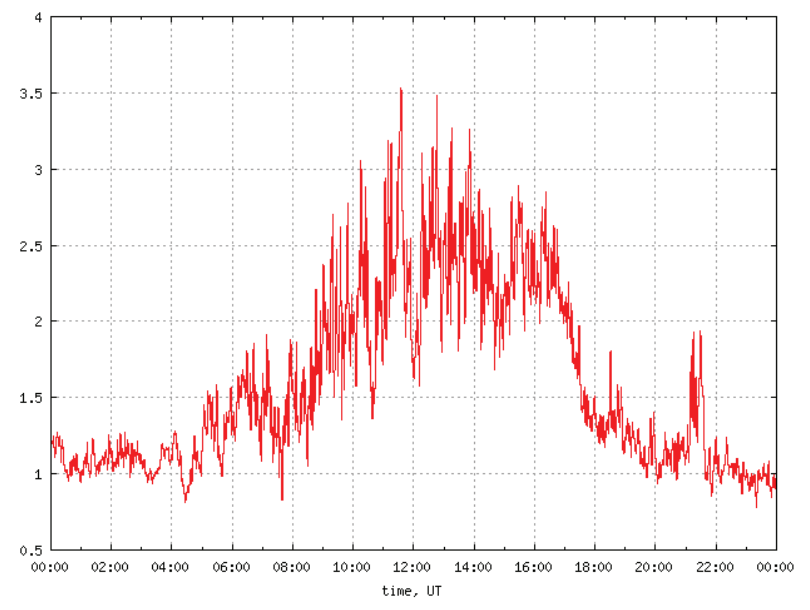

Fig. 12. Graph of unipolarity during the snow on February 26, 2010.

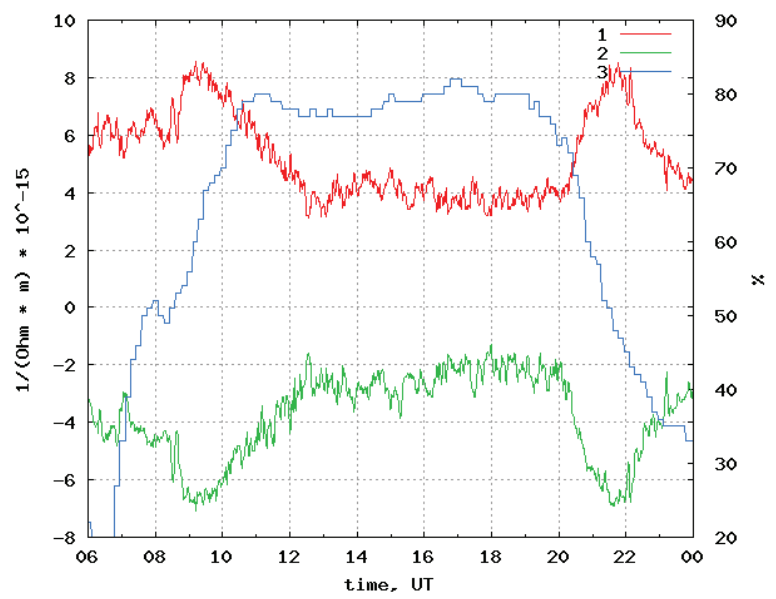

Fig. 13. Fog effect on May 31, 20101 - air electric conductivity is caused by negative ions, and 2 that caused by positive ions with multiplier (-1), left scale, 3 - air humidity, right scale.

only once in August and in November. In September and October, the average number of days with hail is less than 0.1 and the maximal is 2 .

In summer-autumn period, fogs are observed in the region of the observatory. Its effect manifests in the air electric conductivity fall and, consequently, in the increase of the electric field level. Conductivity decreases in fog in the result of attachment of light ions to fog particles so that ion mobility decreases. An example of thick fog on May 31, 2010 is illustrated in Fig. 13. The time of fog development can be judged from the graph of air humidity increase (Fig. 13, curve 3). Whereas, the air electric conductivity caused by negative ions (Fig. 13, curve 1) and positive ions (Fig. 13, curve 2) decreased in a bay-like manner.

Electric conductivity behavior can be explained by the following formula: 


$$
\lambda=e \Sigma\left(n_{i+} u_{i+}+n_{i-} u_{i-}\right),
$$

where $\mathrm{n}$ is the particle concentration and $\mathrm{u}$ is their mobility. Water molecules join to the charged particles of aerosol ions that sharply decreases their mobility. Mobility decrease causes electric conductivity fall.

\section{Seasonality}

Seasonal mode of radon emanation is determined by the value of gas diffusion through the ground. The diffusion is affected by the ground freezing depth in winter time. The depth and the duration of freezing can be judged from the snow cover thickness.

The measurements are carried out on a flat forest clearing, on a plain. The distance to the nearest mountains is not less than $10 \mathrm{~km}$. The snow thickness at the observation point reaches $270 \mathrm{~cm}$ (Fig. 9). Fig. 14 shows the distribution of average monthly values of field intensity and the snow level in the vicinity of "Paratunka" observatory. Snow in the region of observations remains for 7 months (from November to the end of May). The higher the level of snow is and the deeper the ground freezing is, the less radioactive gas emanation is. Thus, the electric field intensity increases.

Electric field measurement point in summer time is mounted at the height of 3 meters. The reduction factor which reduces the field value to the ground level is determined by a special procedure. In order to do that, a second sensor is installed even with the ground and the readings from the two sensors are compared for fair weather days. The reduction factor for Paratunka observatory equals 0.343. In winter time, the snow level almost reaches the level of the sensor. Thus, the reduction factor over a season should change within the range from 0.3 to 1 . However, for the whole period it is excepted to be a constant of 0.343 . That is reflected in the seasonal variation.

Temperature seasonal variation affects the ion mobility that manifests in the air electric conductivity.

It is very difficult to separate the three seasonality factors, the ground freezing factor, the ion mobility change factor and the measurement height point factor.

\section{Electric field secular variation}

20-year observations of potential gradient variations on the days without precipitation showed two intervals where the trend was positive and than negative (Fig. 15).

Fig. 16 illustrates a graph of $\mathrm{M} / \mathrm{lg}(\mathrm{R})$ for the closest earthquakes where $\mathrm{M}$ is the magnitude, $\mathrm{R}$ is the distance to the observatory. Based on Dobrovol'skiy formula, $R=10^{0.43 M}$ [2]. If the value $\mathrm{M} / \lg (\mathrm{R})$ is more than 2.4, the observation point is within the earthquake preparation zone. In terms of this factor, the following earthquakes were the most significant: October 31, 1998. $\left(\varphi=52.95^{\circ} \mathrm{N}, \lambda=158.26^{\circ} \mathrm{E}\right.$, $\mathrm{M}=5.5,2.6 \mathrm{~km}$ from the observatory $), \mathrm{M} / \lg (\mathrm{R})=13.3$ and $\mathrm{July} 29,2000\left(\varphi=52.81^{\circ} \mathrm{N}, \lambda=157.96^{\circ} \mathrm{E}\right.$, $\mathrm{M}=5.4,26.5 \mathrm{~km}$ from the observatory), $\mathrm{M} / \lg (\mathrm{R})=3.8$. Preparation of these two earthquakes was accompanied by a positive trend of the electric field with the angular coefficient of 0.14 and the root-mean-square deviation (RSD) of $307 \mathrm{~V} / \mathrm{m}$. We can suppose that radioactive gas outflow regime changed at that time. After July 2000, the trend became negative with the angular coefficient of -0.16 , RSD was $293 \mathrm{~V} / \mathrm{m}$. 

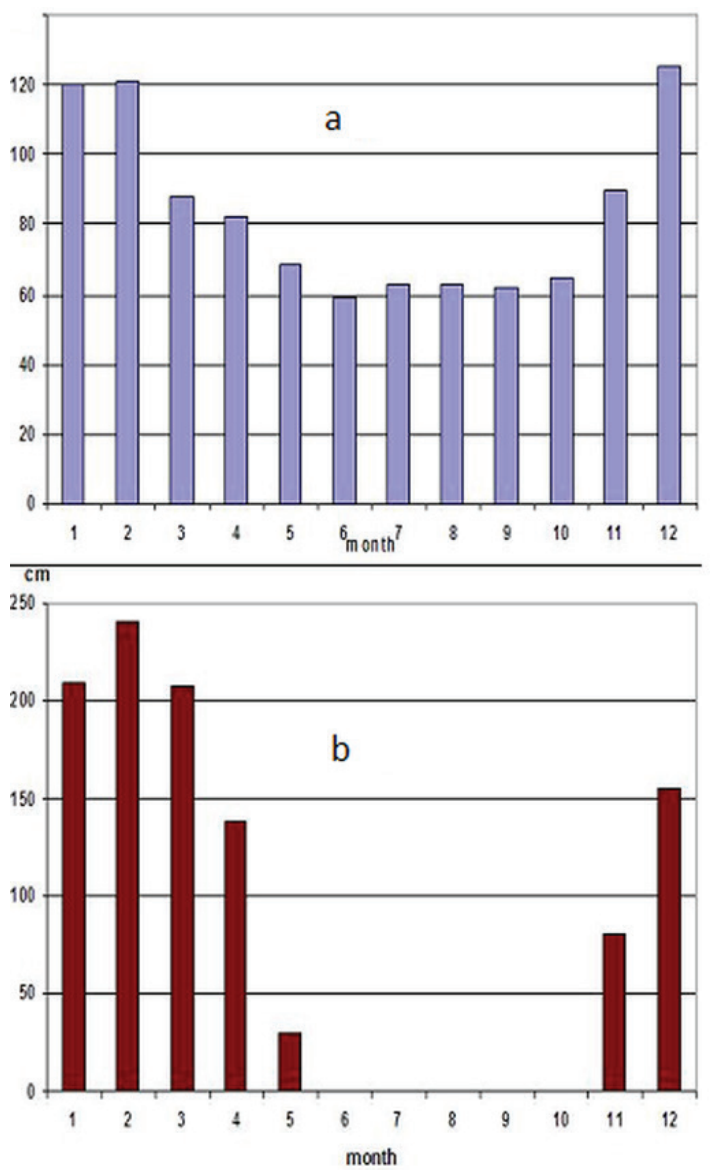

Fig. 14. Histograms of month distribution of electric field intensity (1997-2009) (a) and of snow level (2008-2009) (b) at "Paratunka" observatory.

\section{Discussion of the results}

Light ion mobility $u_{1,2}$ depends on pressure $\mathrm{P}(\mathrm{z})$ and air temperature $\mathrm{T}(\mathrm{z})$ and is determined by the expression [3]:

$$
u_{1,2}=u_{1,2}^{0} \cdot \frac{P(0)}{P(z)} \cdot \frac{T(z)}{T(0)},
$$

where $\mathrm{P}(0)=1013 \mathrm{mbar}$, and $\mathrm{T}(0)=273^{\circ} \mathrm{K}$.

In stationary conditions, ion concentration is determined by the balance equation:

$$
\frac{d n_{1,2}}{d t}=0=q-\alpha n_{1,2}^{2}-\beta n_{1,2} N,
$$

where $\mathrm{q}$ is the ion formation intensity, $\alpha$ is the recombination factor, $\beta$ is the factor of attachment of light ions to aerosol particles, $\mathrm{N}$ is the aerosol particle concentration. 


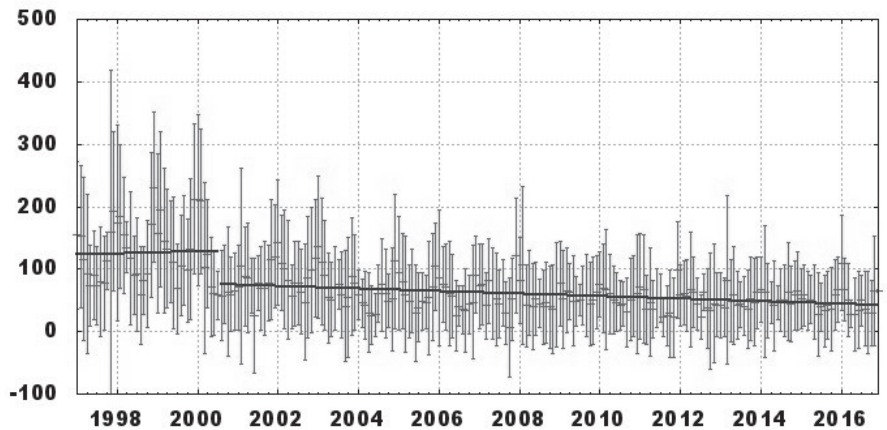

Fig. 15. Potential gradient, root-mean-square deviations and trend lines.

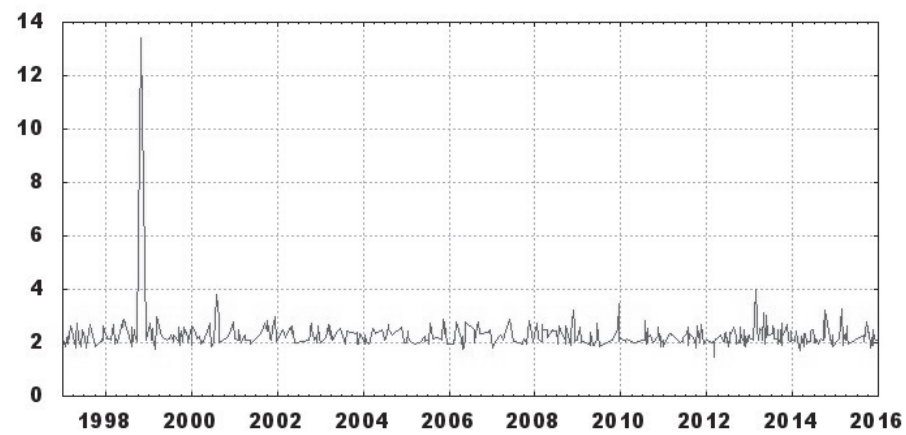

Fig. 16. Graph of earthquakes $M / \lg (\mathrm{R})$, where $\mathrm{M}$-magnitude, $\mathrm{R}$-distance to the observatory.

In stationary cases, excluding the effects of global electric circuit, convective and turbulent processes, we can consider the relation of electric field intensity with air electric conductivity as $E \propto \lambda^{-1}$. In its turn, $\lambda$, according to equation (1), is proportional to ion concentration $(n)$ and mobility $(u)$. The concentration is $n \propto q^{1 / 2}$, and the mobility for large averaging is proportional to temperature $u \propto T$. Thus, seasonal variation of electric field intensity is determined by two processes. In terms of ion mobility, the field intensity is associated with air temperature $E \propto T^{-1}$. And in terms of ion concentration, it is associated with seasonal variation of radioactive gas emanations $E \propto q^{-1 / 2}$.

Kamchatka is one of the most active geodynamic regions. Electric field annual variation can be determined by the annual variation of radioactive gas emanations from one side, and by air pollution of volcanic outbursts, from the other side.

We consider equation (3) more in detail. For example, for positive ion concentration:

$$
\frac{d n_{+}}{d t}=0=q-\alpha n_{+} n_{-}-\beta n_{+} N_{-}-\gamma n_{+} N_{0}
$$

where $N_{-}$is the concentration of negatively charged heavy ions, $N_{0}$ is the neutral particle concentration, $\alpha, \beta, \gamma$ are the corresponding recombination factors. Analogous equations can be written for 
$n_{-}, N_{-}, N_{+}$and $N_{0}$. In the stationary state and in still air, $d n_{+} / d t=0$. Thus,

$$
n_{+}=q /\left(\alpha n_{-}+\beta N_{-}+\gamma N_{0}\right)
$$

We can take into account that $\beta N_{-}+\gamma N_{0}>>n_{-}$and $\beta \approx \gamma$. We denote $N_{-}+N_{0}=N$. On the assumption that approximately $n_{+}=n_{-}$and $u_{+}=u_{-}$, the dependence of electric conductivity on heavy mixture concentration is estimated as follows:

$$
\lambda \sim 1 / N
$$

29 active volcanoes are located in Kamchatka. Field intensity annual variation, except for natural radioactivity, can be determined by volcanic outburst mixture in the air $E \propto N$.

\section{Conclusions}

Based on the analysis of meteorological and climatic parameter effect on the Earth electric field in the near ground atmosphere in Kamchatka, we can conclude that:

1. Precipitation has the greatest impact on electric field intensity variations. To carry out field and observatory measurement, one has to control it as a separate type of observations or by signal form and amplitude.

2. Electric field seasonal variation in the conditions of absence of precipitation is determined by three factors, they are: air temperature affecting the ion mobility, ionization by natural radioactivity affecting the ion concentration in the air, measurement height point change determined by snow cover thickness.

3. Two trends were discovered in the electric field secular variation measured in the conditions of absence of precipitation over the 20-year observation period at Paratunka observatory. From 1997 to July 2000, the trend was positive and then to January 2017, the trend was negative. Natural radioactivity and contaminants in the air from volcano eruptions may affect the secular variation.

\section{References}

[1] Kondratyuk V. I. Climate of Petropavlovsk-Kamchatksiy (Leningrad, Gidrometeoizdat, 1983) 150

[2] Dobrovolsky I.P., Zubkov S.I. Pure Appl. Geophys. 117 1025-1044 (1979)

[3] Brikar Dzh. Radioactivity and pollution effects on atmospheric electricity elements. Problems of atmospheric electricity (Leningrad, Gidrometeoizdat, 1969) 68-105. 